\title{
Fotografía en el aula para el desarrollo del pensamiento histórico
}

\author{
Photography in the classroom for the \\ development of historical thinking
}

DOI: $10.7203 / D C E S .37 .13316$

\author{
Enrique Gudín de la Lama \\ Universidad Internacional de la Rioja, enrique.gudin@unir.net \\ ORCID iD: http://orcid.org/0000-0003-2003-3718 \\ Susana Chávarri Pérez \\ Idéntitas, Historia Corporativa, s.chavarri@identitashc.es \\ ORCID iD: http://orcid.org/0000-0002-9874-1530
}

\begin{abstract}
RESUmen: Hace unos años surgió un nuevo planteamiento didáctico fundamentado en el llamado pensamiento histórico o competencia histórica. La accesibilidad a multitud de archivos fotográficos de diferentes ámbitos y la facilidad que proporcionan las nuevas tecnologías educativas para trabajar con la fotografía, la convierten en un recurso adecuado para la comprensión de la historia a través del trabajo en el aula de las diferentes «competencias históricas». Su rendimiento didáctico dependerá de las estrategias que se utilicen. En nuestro caso consideramos que el planteamiento dialógico y las herramientas didácticas ligadas a las principales competencias históricas constituyen apoyos sólidos para sacar rendimiento didáctico a este material. El artículo expone algunas ideas nucleares sobre competencias que permiten articular el pensamiento histórico: evaluación de evidencias, construcción de narrativas, tiempo histórico y análisis de la causalidad. En torno a ellas se proponen actividades didácticas que ilustran cómo trabajar el pensamiento histórico mediante la fotografía.
\end{abstract}

PALABRas ClaVe: pensamiento histórico, competencia histórica, enseñanza dialógica, didáctica de la Historia, fotografía.

ABSTRACT: A new didactic approach based on the so-called historical thinking or historical competency emerged a few years ago. The accessibility to a great variety of photographic records from different fields and the possibilities that provide the new educational technologies to work with photography make it an appropriate resource for the understanding of History through the engagement of different «historical competencies» in the classroom. Its effectiveness as a didactic material will depend on the strategies used. The dialogic approach and the didactic strategies linked to the main historical competencies are the two foundations that we proposed to obtain all the didactic potential from this type of material. The article presents some core ideas about competencies that allow the articulation of historical thinking: evaluation of evidence, construction of narratives, historical time and analysis of causality. Some didactic activities are proposed around them that illustrate how to work historical thinking through photography.

KEYWORDS: historical thinking, historical competency, dialogic teaching, History instruction, photography.

Fecha de recepción: enero de 2019

Fecha de aceptación: mayo de 2019

Los autores de este artículo son miembros del grupo de investigación "INCISO: La didáctica de las CCSS e Innovación pedagógica en la sociedad digital”, de la Universidad Internacional de la Rioja. 


\section{INTRODUCCIÓN}

Al igual que sucede en otras áreas de conocimiento, hace tiempo que entre los expertos de enseñanza de la historia se detecta una inquietud por la relativa parálisis en la que se encuentra la didáctica de esta materia. Últimamente, los intentos por conseguir que la enseñanza de la historia sea algo más que la mera transmisión -y repetición por parte del alumno- de un determinado relato se están dirigiendo hacia el desarrollo de lo que se ha denominado pensamiento histórico o competencia histórica, expresiones íntimamente relacionadas entre sí, tal como ha expuesto Domínguez (2015). Manifestaciones recientes del giro hacia ese planteamiento han sido el dossier que la revista Annales dedicó en 2015 a esa perspectiva: "Recherche historique et enseignement secondaire" o más recientemente en España "Enseñanza de la historia y competencias educativas" (López, Miralles y Prats, 2017). Aún hay mucho camino por hacer, pero ya se han publicado estudios y propuestas didácticas como los de Girault (2015) o Berthon-Dumurgier (2015) que auguran fructíferos resultados. Por otra parte, Éthier, Demers y Lefrançois (2010) y Arteaga y Camargo (2013), a través de sus pormenorizados análisis han contribuido a centrar el estado de la cuestión respecto al debate sobre al tipo de enseñanza que debe ser la historia. En sus análisis destacan los diseños centrados en la enseñanza del pensamiento histórico.

A esos planteamientos hemos querido añadir los presupuestos de la enseñanza dialógica, una herramienta didáctica que hará más eficaz la adquisición de las competencias históricas por parte de los alumnos.

En cuanto a la fotografía, a pesar de que lleva tiempo presente en nuestra sociedad, apenas se ha explorado su utilización como material didáctico. Consideramos que la didáctica de la historia podía dar un salto de calidad si se consiguiese incorporar al quehacer ordinario del aula un recurso tan atractivo, accesible y eficaz.

En definitiva, el propósito del presente artículo es fundamentar el uso de la fotografía en clase de historia y realizar varias propuestas didácticas que ilustren las posibilidades que ofrece nuestro planteamiento.

\subsection{Enseñar a pensar históricamente}

El buen número de trabajos llevados a cabo por investigadores como Arteaga y Camargo (2013), Carretero y González (2008), Carretero y López (2009, 2011), Lee Dickinson y Asbhy (1998), Lee y Asbhy (2000), Barton (2010), Seixas, Morton, Colyer y Fornazzari (2013), Seixas y Peck (2004), Wineburg (2001) y aquí, en España por Domínguez (2015; 2016), Gómez y Miralles (2013); Gómez, Ortuño y Molina (2014), Pagès y Santisteban (2010), Prats y Santacana (2011), López Facal (2014) o Sáiz y López Facal (2015), López Facal, Miralles y Prats (2017), da idea de la complejidad que lleva aparejada la enseñanza de las competencias históricas y las claves del pensamiento histórico.

Planteamientos concretos de cómo se puede desarrollar una didáctica del pensamiento histórico se pueden visualizar en las webs euroclio.eu; e-story.eu; sheg.stanford.edu; historicalthinking.ca; virtualhistorian.ca; teachinghistory.org historicalthinkingmatters.org, ligadas a los enfoques desarrollados por Lee, Dickinson y Ashby (1998); Wineburg (2001); Seixas et al. (2013).

En esa misma línea, Domínguez (2015) considera que el aprendizaje de la historia no debería consistir tanto en saber «de» historia como saber «hacer» historia. Es decir, el proceso de enseñanza debería articular las estrategias adecuadas que ayudasen a los alumnos a poner en marcha los mecanismos adecuados para entender la realidad histórica que se pretende conocer. La nómina de investigadores que están trabajando en nuestro entorno alrededor de este planteamiento es cada vez mayor como lo muestran los trabajos y publicaciones de Arteaga y Camargo (2013), Gómez et al. 
(2014), Domínguez Castillo (2015), Sáiz y López Facal (2015), Gómez Carrasco, Miralles, López Facal y Prats (2017) Arias, Egea, Sánchez, Domínguez, García y Miralles (2018).

Además del «saber hacer» historia, hay que atender a cómo transmitir los que se han dado en llamar conceptos de primer y de segundo orden. Lee y Ashby (2000) hablan de dos niveles conceptuales en sus reflexiones sobre la enseñanza de la historia; los conceptos de primer orden o sustantivos, aquellos de los que propiamente trata la historia -relativos a procesos históricos concretos: constitución, vasallaje, soberanía, etc.- y los de segundo orden o de procedimiento que proporcionan herramientas y nociones que permiten acceder a la historia como una forma de conocimiento específica: tiempo histórico -analizado por Mora y Ortiz (2013)-, espacio-tiempo, cambio y permanencia, causalidad, evidencia, relevancia y empatía, etc., que constituirían propiamente el campo del pensamiento histórico. Por su parte Carretero y López (2009) -siguiendo a Voss y Wiley (2006)-, enfocan la adquisición del pensamiento histórico desde la perspectiva de los expertos en historia. Consideran que las tres grandes habilidades cognitivas de los expertos en historia -qué habría que enseñar, por tanto, en el marco de este planteamiento- son: la evaluación de evidencias, el pensamiento narrativo, y el razonamiento y solución de problemas en historia. Por su parte Peter Seixas, Penney Clark y su equipo del «the historical thinking project» (http://historicalthinking.ca/) consideran que la enseñanza del pensamiento histórico debe girar entorno a seis conceptos: que los alumnos sepan establecer relevancia histórica, utilizar fuentes primarias, definir la continuidad y el cambio, analizar las causas y consecuencias, adoptar una perspectiva histórica y comprender la dimensión ética de las interpretaciones históricas.

\subsection{Aprendizaje dialógico y rutinas de pensamiento}

Otro eje entorno al que trabajar que ofrece enormes posibilidades es el aprendizaje dialógico. Se trata de una estrategia didáctica de antigua tradición -la mayéutica socrática- que, tras un paréntesis de siglos, ha vuelto a ser considerada en los últimos decenios como una herramienta apropiada no solo para mejorar el proceso de enseñanza-aprendizaje, tal como han sugerido pedagogos como Freire (1977), Bakhtin (1981) o Wells (2001), sino también para profundizar en el saber filosófico de la manera en que lo han planteado filósofos como Habermas (1987) y Searle (1969), o Austin, Strawson, Grice, Chomsky, Goodman y Putnam (Searle, ed.1971).

Su empleo como herramienta didáctica aún sigue siendo escaso, a pesar de algún sugerente desarrollo, como el de Fisher (2013). Su adecuada aplicación en las aulas, a buen seguro, cambiaría las expectativas de los profesores y la motivación de los alumnos. La relación profesor-alumno experimentaría una dinámica más activa y atractiva, alejándose de la escasa sintonía que suele producir el modelo de clase magistral que sigue estando muy presente hoy en día en las aulas.

Un planteamiento que, como defienden Skidmore y Gallagher (citado por Velasco y Alonso, 2008) ofrece un marco claro y adecuado en el que encuadrar el uso de esta herramienta didáctica. Para ellos, la educación dialógica:

[...] se refiere a una clase de relación instructor/alumno en la cual a los estudiantes se les anima a pensar, no simplemente a recordar lo que el instructor expone. [...] [destacan] en cuanto a los métodos en general: (i) el uso por el profesor de preguntas auténticas, (ii) la incorporación de las respuestas de los estudiantes en las preguntas subsiguientes, y (iii) el grado o extensión en que el docente permite que la respuesta del estudiante llegue a modificar el tópico de discusión (Velasco y Alonso, 2008, p. 465).

Se trata, por tanto, de un planteamiento que precisa una constante retroalimentación, lo que supone una exigente implicación por parte del profesor en aras de lograr de los alumnos demandas cognitivas cada vez mayores. Tal como apunta Fisher (2013, p. 58): «esto supone pasar de la pregunta descriptiva acerca del «qué» y el «cómo» a las preguntas de «por qué» y «para qué», que requieren respuestas más complejas». 
Por otra parte, el desarrollo que hizo Lipman (1988) de un planteamiento dialógico para la enseñanza de la filosofía permitió constatar que se trata de una metodología versátil que puede ser adecuada para muchas otras áreas de conocimiento donde las respuestas no son cerradas ni unívocas, como es el caso de la historia. Tal como sugieren Carretero y López, la enseñanza de la historia se puede presentar como «una relación dialéctica de preguntas y respuestas acerca del pasado y su relación con el presente» (2009, p. 78).

El aprendizaje dialógico permite desarrollar hábitos de pensamiento -en este caso relativos a la historia- mediante estrategias propias destinadas, por ejemplo, a peticiones de información, sondear razones y evidencias, examinar puntos de vista diferentes, comprobar implicaciones y consecuencias, etc. del tipo que propone Fisher (2013, pp. 53-34). Por otra parte, los modelos de evaluación que propone Domínguez (2015) -conviene no olvidar que determinados modelos de evaluación pueden dar lugar a diversos modos de aprendizaje- se fundamentan en diferentes tipos de preguntas abiertas dirigidas intencionalmente al objetivo que se busca. Por otra parte, no está de más añadir que, en buena medida, el aprendizaje dialógico está ligado a lo que se conoce como «visible thinking», tal como proponen Kuhn, Hemberger y Khait (2016).

\subsection{Fotografía, fuente histórica primaria}

La fotografía reúne los requisitos más que suficientes para ser considerada fuente historiográfica (Fanelli, 2000; About y Chéroux, 2001: Dorotonsky, 2005). Así la contempló la escuela de Annales, y Haskell (1994) y Burke (2001) han elaborado profundos ensayos sobre la cuestión, al igual que Jaubert (1986).

No obstante, en la práctica casi no se ha utilizado la fotografía como fuente, al menos de forma sistemática tal como lo hace Dewerpe (1987) en su trabajo sobre la organización y el trabajo industrial a comienzos del siglo XX.

Aquí, en España, la revista Ayer publicó en su día un monográfico (Díaz, ed. 1996), pero desde entonces apenas se ha pasado del umbral de la discusión epistemológica sobre la validez de la foto como fuente (Díaz, 2012; Lara, 2005). En nuestro país, el uso de la fotografía para la enseñanza de la historia todavía está en sus comienzos. Se han realizado ya algunos estudios sobre su uso en los libros de texto (Gómez y López, 2014; Carretero y González, 2008; Rodríguez 2010; Pantoja, 2010) y alguna propuesta didáctica (Iglesias, 2009; García 2016), pero aún queda mucho camino por recorrer.

Hasta hace poco la fotografía histórica -y, en general las representaciones gráficas, grabados, cuadros, etc.- se concebía en la enseñanza de la historia como apoyo complementario de las explicaciones. No obstante, tal como sostiene Lanzardo (1991), se puede utilizar la fotografía como respuesta a las propias hipótesis o para contrastar la documentación escrita, o, yendo más lejos aún, apoyarse en ella y en las fuentes visuales como soportes del discurso histórico (Díaz, 2012). Con la fotografía se pueden fundamentar afirmaciones históricas del mismo modo que se hace con la documentación escrita. En un momento en que la investigación histórica tiende a ser global, apoyada en fuentes tanto orales como escritas y objetuales, la fotografía debería pasar a ser una fuente más, que habría que tratar con el mismo sentido crítico que el resto de las fuentes, con su propio aparato crítico y de lectura, tal como ha analizado detenidamente Burke (2001).

\section{Fotografía en Clase de historia. ¿Por dónde empezar?}

Tal como se ha expuesto en la introducción, el presente artículo no pretende únicamente realizar una sucinta reflexión teórica sobre el uso de la fotografía como material didáctico para la enseñanza de la historia, sino también mostrar cómo puede llevarse a cabo mediante alguna propuesta didáctica. Tal como proponen Sáiz y Domínguez (2017), consideramos que es posible el aprendizaje de la historia mediante conocimientos del propio pasado, "pero también mediante 
competencias cognitivas específicas de la historia disciplinar” (Sáiz y Domínguez, 2017, p. 23), de ahí que empecemos haciendo un repaso de las principales propuestas prácticas para trabajar competencias históricas y planteemos a continuación una serie de actividades siguiendo en parte las propuestas de Kitson, Steward y Husbands (2015, pp. 85-132) y Saiz y Dominguez (2017, pp. 2347).

\subsection{Evaluar evidencias}

El primer paso para que el alumno pueda percibirse a sí mismo como historiador es que se enfrente a las fuentes históricas. Ashby, Lee y Shemilt (2005, p. 166) consideran que el primer nivel de comprensión de pruebas históricas es el de imágenes -fotografías- del pasado, y así queda plasmado en buena parte de los proyectos online que hemos citado.

Ya hemos comentado que la fotografía es, en muchos casos, una evidencia histórica, es decir, posee el valor del testimonio directo, uno de los criterios imprescindibles para hacer historia. Además, como fuente primaria tiene la ventaja de ser accesible de manera más natural -en cuanto a su «lectura»- a los alumnos de hoy en día que otros documentos primarios.

Gervereau (2004) propone para el trabajo con la fotografía un esquema basado en su localización, análisis, clasificación e inferencia de la información que hay implícita, una estrategia similar para la enseñanza-aprendizaje de la historia al planteado por Prats y Santacana (2011). Prescindiendo del trabajo de localización -que puede dar lugar a pequeñas investigaciones en los «archivos fotográficos familiares»- el trabajo de análisis y clasificación, por muy elemental que sea, permite trabajar con destrezas como el juicio crítico para discernir su perspectiva, su fiabilidad o su nivel de tergiversación de los hechos y poder interpretar las imágenes adecuadamente. De esta forma se pueden realizar inferencias razonables y coherentes en relación con los datos de que se dispone.

Un trabajo complementario a la localización es la motivación que dio lugar a la imagen, objeto de constantes reflexiones por parte de Burke (2001), quien considera que desentrañar el porqué se realizó es esencial para dar sentido a una imagen.

Por su parte, Rodríguez (2009, 2010), partiendo de la interpretación de la fotografía como un fragmento de tiempo y espacio, propone una metodología propia en la que los principales jalones serían la extracción de información, la observación y análisis, la creación de relaciones, la percepción de los procesos y el ejercicio de la abstracción.

\section{Observación y análisis}

Fisher (2013) considera que «solo mediante el diálogo se puede aprender a ser crítico y a estar preparado para evaluar la evidencia» (Fisher 2013, p. 115). Para ello propone que ante una evidencia y para mantener la mente abierta, los alumnos tendrían que ser capaces de hacerse preguntas como: ¿quién dice esto? ¿qué dice? ¿cuál es el quid de la cuestión? ¿por qué dice eso? ¿qué significa? ¿qué más necesito saber? Se trata de una versión del clásico who, what, where, when, why, que proponen Denos y Case (2006) al hilo del magisterio de Seixas, y que ha sido recogido en muchas de las lecciones en «the historical thinking project» -historicalthinking.ca-. En el proyecto se desglosan esos interrogantes mediante preguntas que permiten centrar (y analizar) adecuadamente el contenido de cada imagen: quién: ¿quién está en la imagen?, ¿quién usaría este objeto?; qué: ¿qué está haciendo la gente?, ¿cuál es este objeto?; dónde: ¿dónde se lleva a cabo esta acción?, ¿dónde se utilizaría el objeto?; cuándo: ¿cuándo se llevará a cabo esta acción?, ¿cuándo se utilizaría el objeto?; ¿por qué?: ¿por qué están haciendo esto? ¿por qué se utilizaría el objeto? ¿cuál es su función?; cómo: ¿cómo llegó esta gente a estar en esta situación? ¿cómo fue creado y utilizado ese objeto?. 
En el grupo History Education de Standford -sheg.stanford.edu- las cuestiones iniciales que proponen ante cualquier documento son: ¿quién escribió esto?, ¿cuál es la perspectiva del autor?, ¿por qué se escribió?, ¿cuándo se escribió?, ¿dónde se escribió?, ¿es creíble?, ¿por qué?, ¿por qué no?, preguntas en las que se puede sustituir perfectamente la alusión al documento escrito por una referencia a la fotografía que se tenga delante.

\section{«Entrar» en la foto: contextualización y explicación por empatía}

Otra tarea imprescindible con cualquier fuente histórica es su contextualización. En relación con nuestro planteamiento es igualmente imprescindible pues con ella se persigue que los alumnos puedan darle un sentido a la conducta humana y puedan comprender modos y estilos de vida que hoy en día no son habituales e incluso pueden parecer absurdos. A este respecto hay que tener en cuenta que la empatía no implica identificación o afinidad en los sentimientos, sino un ponerse en «lugar de» desde una perspectiva intelectual (Foster, 2001). La empatía permite proponer el significado más legítimo de una determinada acción en un contexto histórico concreto. Para Lee y Shemilt (2011) se llega apoyándose en las fuentes para reconstruir creencias y valores de otra época, de forma que se hagan inteligibles sus actuaciones y prácticas sociales.

Una forma de «empatizar» con un contenido es reproducir en el aula la escena de la fotografía (de una reunión, de una acción, de una fiesta...) de la forma más realista posible. Incluso la reproducción del vestuario o del mobiliario -aunque sea imitándolos- permitirá que los alumnos se hagan preguntas más allá de las modas de una determinada época. Podrán plantearse los porqués de los modos de hacer de una sociedad determinada: el porqué de los gestos, miradas, acciones, posición en la foto, etc. de tal manera que los alumnos, al resolver esas preguntas, alcancen a comprender mejor la trabazón que sustenta la mentalidad de una época.

«Hacer hablar» a las fuentes (Domínguez, 2015)

La tarea del historiador no se reduce al mero «desempolvar» documentos. Ha de interrogar las fuentes para averiguar algo razonablemente cierto sobre lo ocurrido, sin aceptar sin más como hechos y datos ciertos los que proponen las fuentes (Wineburg, 2001). De la misma forma habrá que actuar con las fotografías: una vez analizadas, clasificadas y contextualizadas, llegará el momento de inferir evidencias históricas a partir de ellas (Seixas et al., 2013). Teniendo presente, además, que:

En la construcción del objeto de estudio [el pasado] por los historiadores existe cierto grado de subjetividad, consecuencia del contexto social, cultural, económico o político. Por ello es tan importante insistir en que las huellas, fuentes y evidencias del pasado son muy útiles para la reconstrucción histórica (Gómez et al., 2014).

El proyecto historicalthinking.ca propone una primera aproximación a esta tarea mediante el siguiente cuestionario: ¿a qué preguntas sobre el pasado nos ayuda a responder esta fuente?; ¿qué respuestas podemos inferir de esta fuente para responder a esas preguntas?; ¿qué evidencia hay en esa fuente capaz de apoyar nuestra respuesta?; ¿qué nos dice? ¿qué otra (u otras) evidencia necesitamos?

También es interesante la propuesta del Archivo Histórico Nacional en torno a la guerra de Independencia -pares.mcu.es/GuerraIndependencia/portal/aprendiz/aprendiz- donde se proponen análisis de imágenes de aquella época de acuerdo con algunos de los criterios parecidos a los que acabamos de anotar.

Domínguez (2015) habla de «convertir fuentes en pruebas» considerando que, para ello, «la información que se puede obtener depende casi totalmente de las preguntas que se formulen» (Domínguez, 2015, p. 69), y para ello desglosa la tarea en cinco destrezas de lectura y 
comunicación: obtener información explicita, obtener información por inferencia, integrar e interpretar, evaluar y comunicar y sintetizar (Domínguez, 2015, p. 91, pp. 94-99). En esa misma dirección apunta el proyecto historicalthinkingmatters.org, añadiendo ejercicios en los que se compara la fotografía con la información proporcionada por otras fuentes -escritas, objetuales- para establecer puntos de acuerdo y desacuerdo.

En todo caso, el profesor es clave para la puesta en marcha de esta estrategia. La formulación por su parte de las preguntas convenientes permitirá que el alumno extraiga de las fotos la información necesaria para sacar conclusiones que estén más allá de lo que se advierte a primera vista.

\subsection{Ejemplo de actividades sobre “mujeres en la I Guerra Mundial”: evaluar evidencias mediante la observación y análisis; entrar en la foto y hacerla hablar}

La propuesta de actividades que hacemos a continuación está dirigida a alumnos de $4^{\circ}$ ESO $1^{\circ} \mathrm{BAC}$, ya que la I Guerra Mundial está incluida en su temario y se puede recurrir al libro de texto para complementar las informaciones y datos que haga falta para contextualizar alguno de los aspectos. El objetivo de la actividad no es tanto "hacer historia” sino más bien comprenderla. No "validar" lo que dicen los libros de texto sino asomarse un poco más allá. Es decir, no se trata de suplantar a los manuales sino de abrir una ventana a una perspectiva histórica, a lo que se llama pensamiento histórico.

Actividad 0: antes de empezar.

En la siguiente foto tienes un grupo de personas celebrando el final de la IGM. Junto a la foto te proponemos algunas cuestiones relativas a su contenido.

IMAGEN 0: Soldiers celebrating peace after World War I

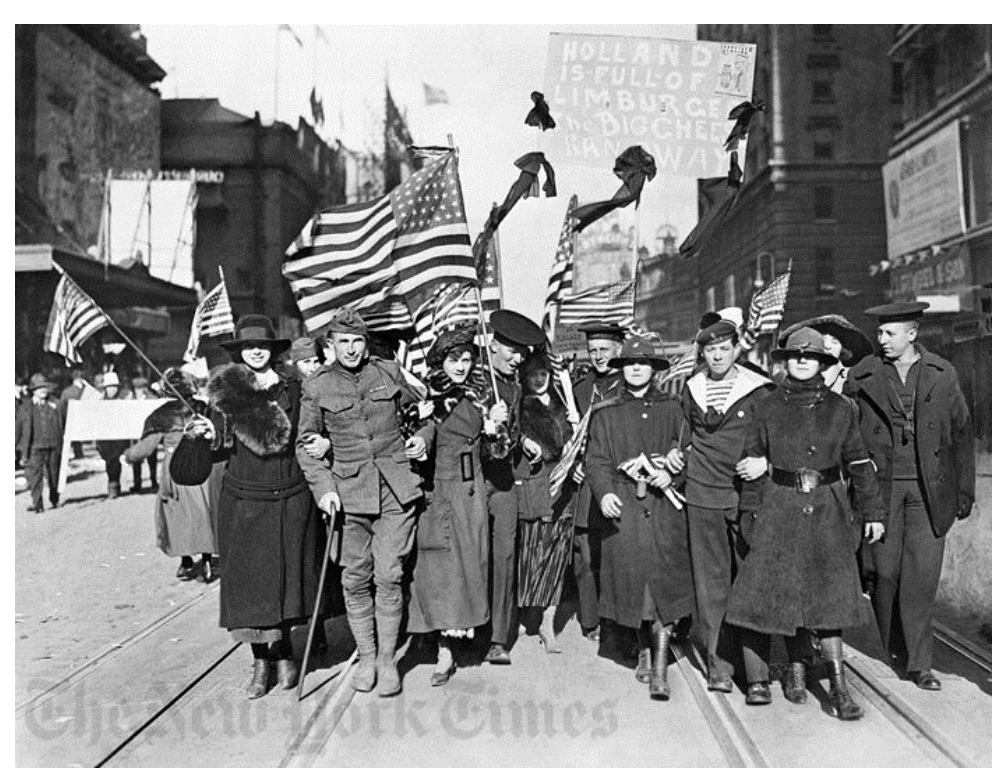

Fuente: Hulton-Deutsch Collection/CORBIS/Corbis via Getty Images
¿Cuántos hombres y mujeres hay en el grupo de la foto?

Entre los hombres hay militares de distintas armas. ¿Sabrías decir de cuáles? ¿en qué detalles te basas?

También hay mujeres. ¿Hay alguna que desempeñe funciones militares o parecidas? ¿Cómo lo sabes?

¿Quién crees que tiene más derecho a celebrar el final de la guerra, los hombres o las mujeres? ¿por qué? ¿Piensas que las mujeres pudieron participar de manera eficaz en la guerra, o sea, influir en su desarrollo, o su contribución fue más bien pequeña? ¿Por qué?

Actividad 1:

- Actividad 1A-. A continuación te mostramos una serie de fotos con algunas actividades que desempeñaron las mujeres a lo largo de la I Guerra Mundial. Te pedimos que describas lo más exactamente posible cada una de ellas (en qué sitio están, qué objetos o herramientas aparecen, 
cómo van vestidas), la actividad que realizan y después ponle un título que ilustre lo mejor posible la escena.

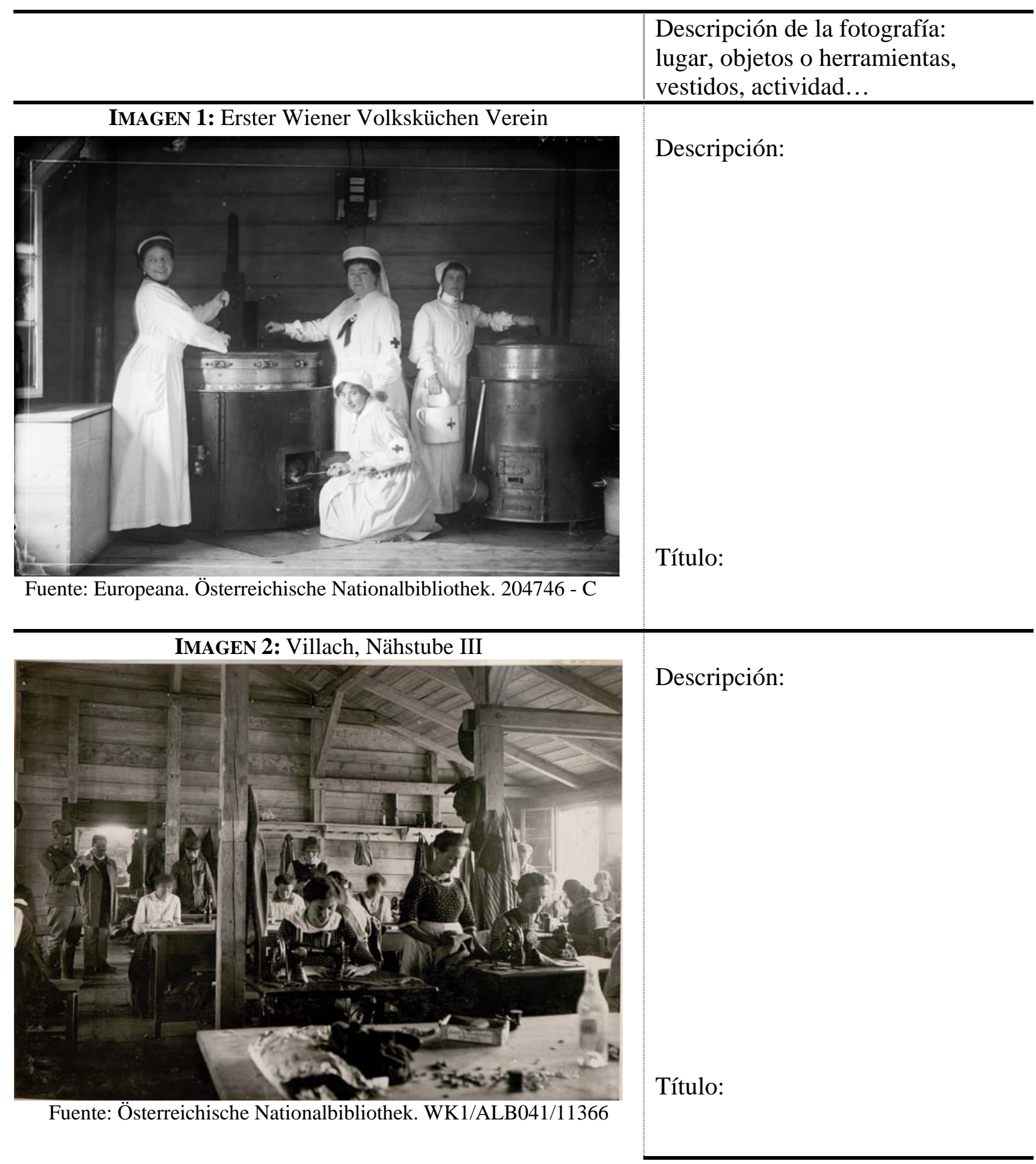




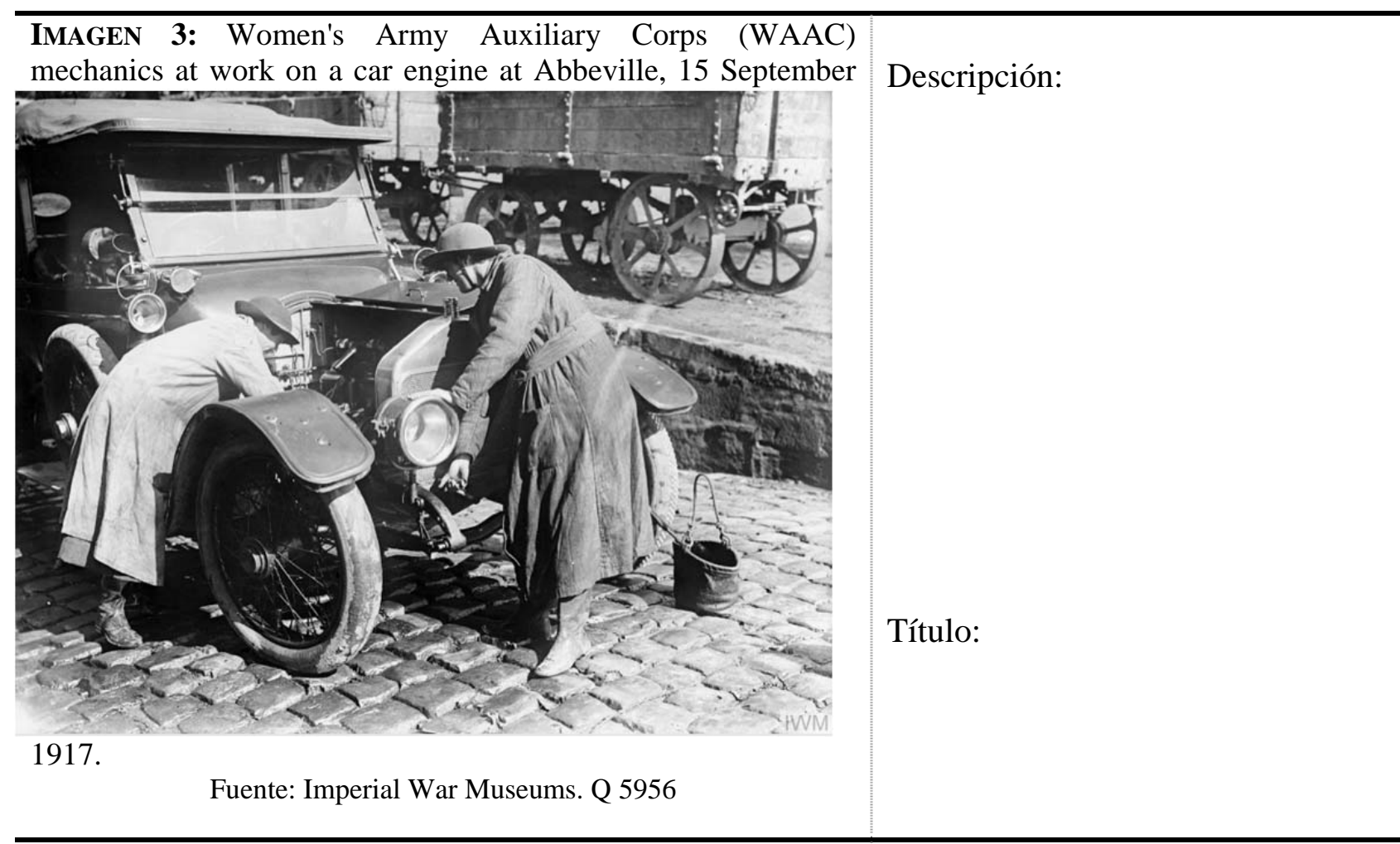

IMAGEN 4: Woman working in a National Filling Factory at Banbury, Oxfordshire.

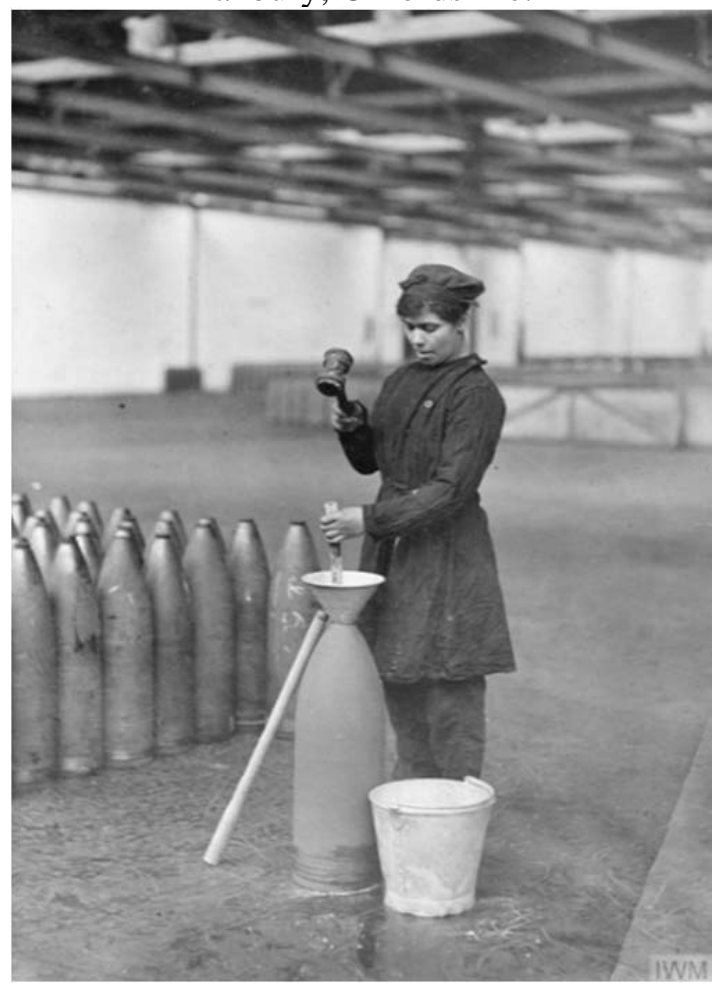

Descripción:

Fuente: Imperial War Museums. Q 70679

Título: 


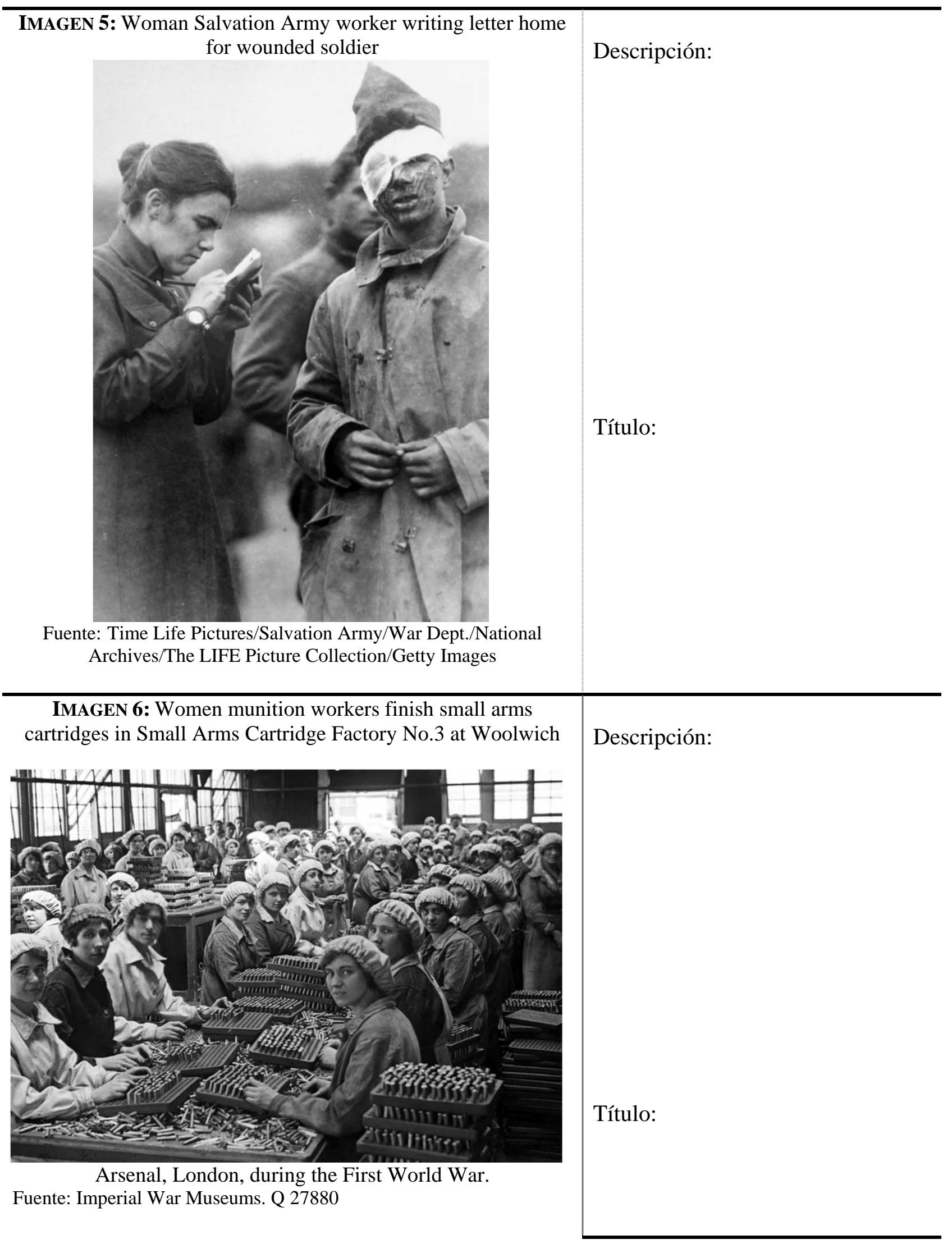




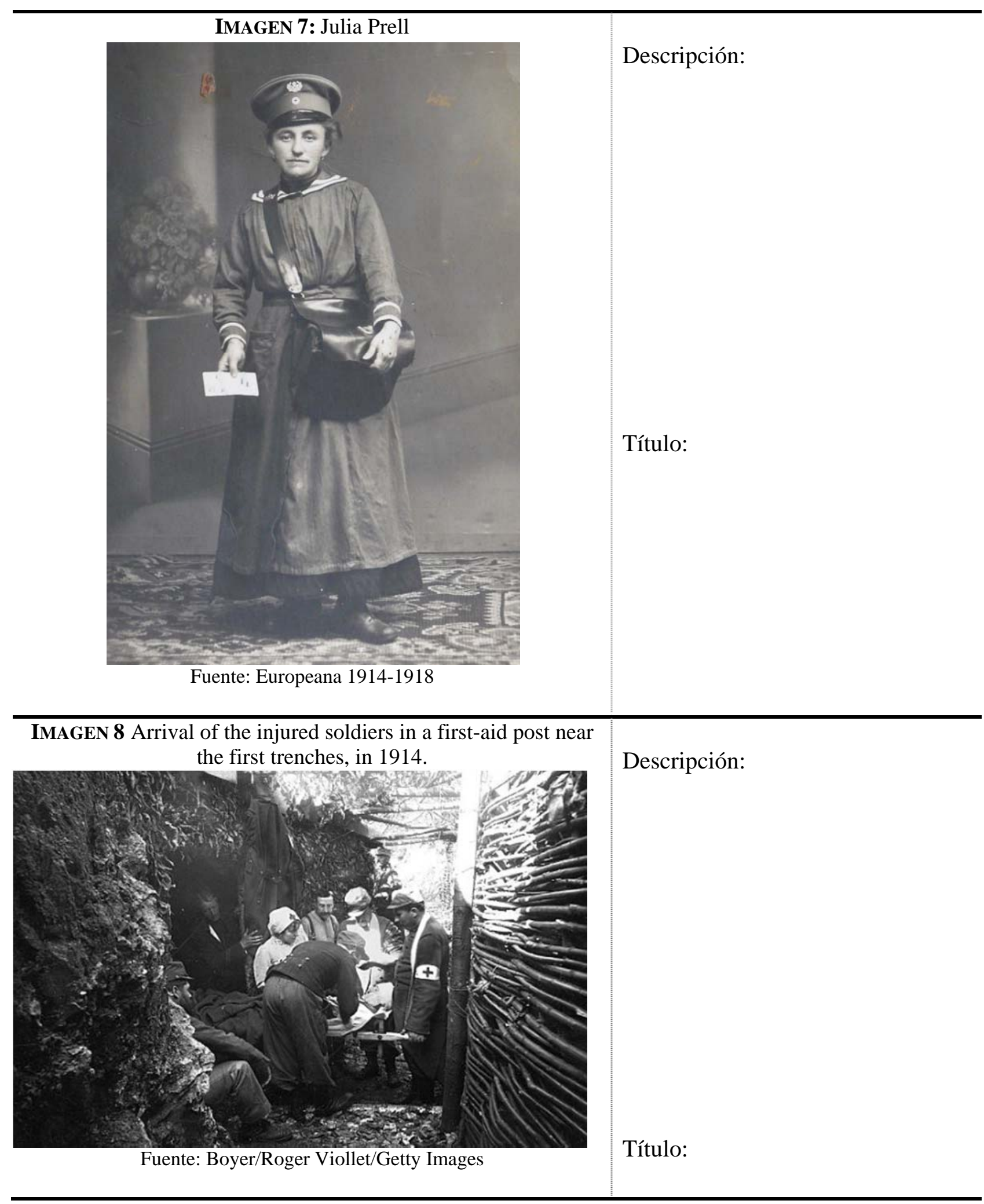


-Actividad 1B-. Una vez que has descrito las distintas actividades, ordénalas en función de su relación más o menos directa con las tareas de la guerra, primero las más importantes para la guerra y al final las que menos influyeron en el desarrollo de la guerra. Después explica por qué has establecido ese orden.

-Actividad 1C-. Piensa ahora cuál de esas actividades, si no se hubiese llevado a cabo, habría imposibilitado sostener la guerra y, por tanto, el país habría tenido que retirarse de la guerra o rendirse. Explica por qué.

-Actividad 1D-. Ahora vamos a afinar un poco más. De todas esas actividades, ¿hay alguna que no fuese del todo necesaria, que se podría haber dejado de hacer y la guerra habría seguido igual?

\section{UN PASO MÁS ALLÁ: CONSTRUCCIÓN DE NARRATIVAS, TIEMPO HISTÓRICO, ANÁLISIS DE LA CAUSALIDAD}

\subsection{Fotografía y relato histórico}

El nivel de competencia narrativa del alumnado es un componente clave del pensamiento histórico y social (Sant et al., 2014). La culminación, en sentido estricto, de la tarea del historiador es contar qué ha sucedido y por qué ha ocurrido así y no de otra manera. Es decir, narrar lo sucedido argumentando mediante los distintos elementos del pensamiento histórico que se han ido poniendo en juego a lo largo de la investigación.

Voss y Wiley (2006) consideran que la construcción de narrativas válidas sobre un evento determinado debe reunir cinco rasgos: coherencia, cronología, exhaustividad, contextualización y causalidad. Y recoger y analizar, además, las narrativas alternativas.

Una narración histórica trazada sobre el recorrido cronológico de lo que se quiere relatar es insuficiente. En historia, la técnica narrativa no difiere mucho de la que se suele utilizar en la literatura, obviando, lógicamente, que el material narrativo no es fruto de la imaginación, sino de la investigación histórica. El relato histórico tiene la finalidad de comprender y dar sentido a los hechos investigados por el historiador, no uno a uno, sino en su conjunto. Para ello, aparte de la selección de factores, acciones, personas, hechos, circunstancias, etc., es imprescindible establecer la red de conexiones y la jerarquía que hay entre ellos, a partir de la cual se podrá abordar la construcción narrativa (Saiz y López, 2015).

Mattozzi (2004) señala diferentes aspectos que conviene tener en cuenta a la hora de elaborar el relato histórico: en primer lugar «tematizar» el hecho histórico, es decir, ponerle un nombre y adscribirlo a un periodo y lugar bien definidos, lo que ayudará «a los alumnos a entender qué tema tienen que estudiar, qué significado se les quiere transmitir, cuál es la arquitectura temática que hace posible la comprensión y la construcción». (Mattozzi, 2004, p. 41).

Por otra parte, el trabajo de reconstrucción narrativa depende del tipo de acontecimiento del que se trate. Predominará lo descriptivo o lo narrativo dependiendo del problema del que se trate, de sus posibles explicaciones, etc.

En cuanto a los alumnos de secundaria o bachillerato, la principal dificultad con la que se encontrarán para la construcción de narrativas históricas es la necesidad de fundamentar su explicación en inferencias o deducciones realizadas sobre nexos no documentables. Tendrán que establecer nexos (causales o contrafácticos) que den sentido a la secuencia que se quiere narrar y que no resultan fáciles de detectar en la superficie de los acontecimientos.

No obstante, existen estrategias eficaces para iniciar a los alumnos: la narración mediante etiquetas o la realización de documentales (videos) basados en fotografías -actuales e históricas, lo que se suele denominar historia gráfica-, etc. Son fáciles de llevar a la práctica hoy en día mediante 
una tecnología digital perfectamente asequible -tanto económica como técnicamente- que permite realizar esas pequeñas producciones audiovisuales. También se pueden realizar narraciones digitales «digital storytelling» mediante aplicaciones online.

\subsection{Razonamiento histórico: tiempo histórico, cambio y continuidad}

Esta tríada de conceptos está asociada entre sí. La referencia a uno hace comprensibles los otros dos. Una vez contextualizado el hecho -o una mentalidad, una forma de ver la realidadresulta más sencillo comprender la rapidez o lentitud con la que cambia... o se mantiene en el tiempo; igualmente facilita la valoración de si los cambios han traído progreso o retroceso, aspectos esenciales del pensamiento histórico (Domínguez, 2015). La comparación es una estrategia (Pagès, 2006) que puede facilitar la fotografía, pues el cambio y la continuidad son fácilmente detectables en los materiales visuales.

Domínguez (2015) propone, asimismo, abordar el cambio y la continuidad de los hechos desde distintos ángulos: el de su contenido -qué cambia o permanece-, el de su explicación -qué causas y acciones humanas los impulsaron o no-, el de sus procesos -cómo cambian: rápida, lentamente, etc.- y el de su valoración y orientación -¿trajo o no progreso el cambio?, ¿en qué sentido?-.

Resultará más accesible el planteamiento de esas cuestiones si se escogen adecuadamente imágenes o fotografías que ayuden a ilustrar las diferencias que se han dado en esos procesos. Serán más fáciles de analizar las que se refieran a procesos externos: modas, instrumentos, vehículos, etc. pero también será posible establecer comparaciones entre escenas de guerra, modos parlamentarios, representaciones familiares, manifestaciones públicas, etc. que permitirán valorar aspectos más profundos de los cambios.

\subsection{La explicación causal de la historia mediante la fotografía}

Un magnífico ejemplo de cómo puede llevarse a cabo una didáctica dialógica de la explicación causal se encuentra en las pruebas de Ciencias en PISA liberadas en 2010 (Ministerio de Educación, 2010). En concreto las relativas al «Diario de Semmelweis» (pp. 17-21), en las que se propone la investigación de las causas de la fiebre puerperal en un sanatorio del siglo XIX.

Lipman propone en su «Investigación filosófica» (1988, pp. 416-428) diversos acercamientos a la conceptualización de la relación causa-efecto que pueden ser útiles, a pesar de que se fundamenten en un análisis lingüístico de las proposiciones. Se trata de ejercicios que ayudan a que los alumnos valoren diversas posibles combinaciones causa-efecto, la relación entre efectos, causas y tiempo, o la distinción entre explicación y descripción o causa y razón. Todos ellos fundamentados en estrategias dialógicas.

La explicación causal de cualquier hecho es difícil; el hecho de que haya una conexión entre dos acontecimientos no implica que tenga que haber una causa; además, las relaciones de causalidad no son inmediatas, no tiene por qué haber entre ellas ni continuidad ni contigüidad. Hay que diferenciar entre causa y condición y habitualmente no actúa una sola causa en la producción de un hecho. En el caso de la historia se añade además que el intervalo temporal entre causa y efecto suele ser grande y no se aprecia a primera vista (Hernández, 2002).

Las principales tareas que habrá que abordar (Domínguez, 2015, p. 110) serán la selección de los hechos más relevantes de aquello que se quiere explicar y establecer los que han podido ser determinantes mediante un juicio contrafáctico (Carretero y López, 2009, p. 82). A continuación, establecer el tipo de relación que hay entre causa y efecto; después clasificar las causas siguiendo, por ejemplo, la propuesta de Chapman (2003): según su contenido o ámbito -económicas, políticas, culturales, etc.-; según su duración temporal -largo, medio, corto plazo-; según su función e importancia específica -determinante, condicionante, desencadenante-; o según su peso o 
importancia. Por último, elaborar la síntesis y la hipótesis que permita explicar y evaluar el acontecimiento que se ha analizado.

La fotografía permite realizar con cierta fortuna este tipo de análisis de las causas, sobre todo en el caso de las series fotográficas o los reportajes de un mismo acontecimiento. De alguna manera, estaríamos ante un tipo de enseñanza similar a la que se puede derivar del concepto cinematográfico de montaje: desde jugar con el orden cronológico de la serie, hasta su ordenación de distintas maneras permitiendo una lectura coherente, aunque falsa. Así, se les podría hacer comprender a los alumnos la importancia de la sucesión de acontecimientos, la diferencia entre continuidad y causalidad y también el sentido de la multicausalidad.

\subsection{Ejemplo de actividades sobre “mujeres en la I Guerra Mundial”. Construcción de narrativas, tiempo histórico, análisis de la causalidad}

Seguimos con las fotografías de las mujeres en la I Guerra Mundial que hemos utilizado más arriba. Completamos así con el mismo material didáctico el trabajo con el resto de las habilidades de pensamiento histórico a las que hemos aludido.

-Actividad 2A-. Las fotografías con las que has trabajado en las actividades anteriores no siguen ningún orden especial. Ordénalas con criterios cronológicos en función del desarrollo de la guerra (algunas no será fácil decir a qué momento exacto corresponden, por lo que tendrás que decidir basándote en argumentos que elabores tú). Después construye una narración -sencilla, pensada para alumnos de primaria- en la que relaciones unas con otras siguiendo el desarrollo de la guerra.

-Actividad 2B-. ¿Piensas que algunos de los trabajos que realizaron las mujeres en la I Guerra Mundial podrían desarrollarlos las mujeres hoy en día si hubiese una Guerra Mundial? ¿querría decir eso que estamos en la misma época histórica que ellas? Con los conocimientos que tienes de la Edad Media, ¿desarrollaron las mujeres el mismo tipo de trabajos en las guerras de aquella época? ¿cuáles sí y cuáles no? ¿a qué crees que se puede deber que se hayan mantenido algunas de las tareas y se hayan incorporado otras nuevas?

-Actividad 2C-. Si tuvieses que razonar la importancia que tuvo la mujer en la I Guerra Mundial, qué argumentos utilizarías basándote en las fotos. Elabora una pequeña exposición que comience de la siguiente manera: "si las mujeres en la I GM se hubiesen quedado todas en sus casas...”

-Actividad 2D-. Si tu hubieses sido un soldado de la I Guerra Mundial ¿cuál de las tareas que aparecen en las fotografías te habrían parecido más importantes para ti o tus compañeros de las trincheras?

Pero, independientemente de las actividades de las mujeres que les hubiesen venido bien a los soldados ¿cuáles habrían sido imprescindibles para que se pudiese ganar la guerra?

Si tu hubieses vivido en la I Guerra Mundial ¿¿cuál de las tareas de las que aparecen en las fotos se te habría dado mejor? ¿qué habrías hecho? ¿te habrías dedicado a esa tarea aunque no fuese la más importante para la guerra o te habrías alistado en el ejército?

-Actividad 2E-. De todas esas tareas, ¿cuál no era imprescindible para el desarrollo de la guerra? es decir, ¿cuál se habría podido dejar de hacer y no habría afectado para nada al desarrollo de la guerra, la guerra habría continuado como si tal cosa? Y ahora piensa en el panorama contrario ¿cuál de esas actividades -si se hubiese dejado de hacer- habría puesto fin a la guerra? o sea, no 
habría habido posibilidades de que la guerra continuase de ninguna manera. Explica lo que piensas al respecto argumentándolo.

\section{Conclusiones}

La fotografía es una fuente histórica de fácil acceso tanto para investigadores como para docentes, sin embargo, todavía se utiliza poco en investigación y en docencia.

Su uso para la enseñanza de la historia resulta perfectamente adecuado en el ámbito de la enseñanza por competencias y en concreto para abordar la adquisición de la competencia histórica o pensamiento histórico- por parte de los alumnos de secundaria y bachillerato.

Para llevar a cabo propuestas didácticas en esa dirección son adecuados los planteamientos de la educación dialógica, los correspondientes al análisis propio sobre la fotografía (a un nivel adecuado a los alumnos de los que se trate) y el enfoque por competencias, en concreto desde la competencia histórica.

La enseñanza dialógica permite una interacción con el alumno que facilita tanto el acercamiento al objeto de estudio (en este caso el contenido de la fotografía) como la implicación del alumno en su propio aprendizaje. Por su parte, las estrategias propias del análisis de la fotografía permiten enmarcar el objeto de estudio sin desviaciones y en su propio ámbito de estudio, lo que facilita llevar a cabo en el aula un trabajo concreto y definido, sin dispersiones. Y en lo que se refiere al trabajo sobre pensamiento histórico abre un panorama enriquecedor con relación a los planteamientos actuales de la didáctica de la historia centrada más en la memorización y reproducción de los relatos.

\section{Referencias}

Arias, L., Egea, A., Sánchez, R., Domínguez, J., García, F. J. y Miralles, P. (2018). ¿Historia olvidada o historia no enseñada? El alumnado de Secundaria español y su desconocimiento sobre la Guerra Civil. Revista Complutense de Educación, 30(2), 461-478.

Arteaga, B. y Camargo, S. (2013). Educación histórica. Una propuesta para el desarrollo del pensamiento histórico en los estudiantes de licenciatura en educación preescolar y primaria. En Historia e identidades culturales (pp. 220-233). Braga: Universidad do Minho.

Ashby, R., Lee, P. y Shemilt, D. (2005). Putting principles into practice: teaching and planning. En Donovan, M. S. y Bransford, J. D. (eds.), How students learn: History in the classroom. Washington DC: The National Academies Press.

Bakhtin, M. M. (1981). The dialogic imagination: Four essays. Austin: University of Texas Press.

Barton, K. C. (2010). Investigación sobre las ideas de los estudiantes acerca de la historia. Enseñanza de las ciencias sociales: revista de investigación, 9, 97-113.

Berthon-Dumurgier, A. (2015). Apprentissages historiques et métier d'historien. Un parcours de compétences. Annales. Histoire, Sciences Sociales, 70(1), 161-170.

Burke, P. (2001). Eyewitnessing. The Uses of Images as Historical Evidence. Londres: Reaktion Books.

Carretero, M. y González, M.F. (2008). Aquí vemos a Colón llegando a América. Desarrollo cognitivo e interpretación de imágenes históricas. Cultura y Educación, 20(2), 217-227

Carretero, M. y López, C. (2009). Estudios sobre el aprendizaje y la enseñanza de la Historia: implicaciones para el desarrollo de la alfabetización histórica. Ciências \& Letras, 49, 139155.

Chapman, A. (2003). Camels, Diamonds and Counterfactuals: a model for teaching causal reasoning. Teaching History, 112, 46-53.

Chéroux, C. (2001). L'histoire par la photographie. Études photographiques, 10, 8-33. 
Davis, O. L., Yeager, E. A. y Foster, S. J. (eds.) (2001). Historical empathy and perspective taking in the social studies. Rowman \& Littlefield.

Denos, M. y Case, R. (2006). Teaching about historical thinking. Vancouver: The Critical Thinking Consortium.

Dewerpe A. (1987). Miroirs d'usines: photographies industrielles et organisation du travail à l'Ansaldo (1900-1920). Annales. Économies, Sociétés, Civilisations, 42(5), 1079-1114.

Díaz, M. (2012). La imagen en el tiempo: el uso de las fuentes visuales en Historia. Historia Actual Online, 29, 141-162.

Díaz, M. (ed.) (1996). Monográfico “Imagen e historia”. Ayer, 24.

Domínguez, J. (2015). Pensamiento histórico y evaluación de competencias. Barcelona: Graó.

Domínguez, J. (2016). Enseñar y evaluar el pensamiento histórico. Competencias, conceptos y destrezas cognitivas. Iber. Didáctica de las ciencias sociales, Geografía e Historia, 82, 4349.

Dorotonsky, D. (2005). La fotografía como fuente histórica y su valor para la historiografía. Revista Fuentes Humanísticas, 17(31), 117-140.

Éthier, M.A., Demers, S. y Lefrançois, D. (2010). Las investigaciones en didáctica sobre el desarrollo del pensamiento histórico en la enseñanza primaria. Una panorámica de la literatura publicada en francés e inglés desde el año 1990. Enseñanza de las ciencias sociales, 9, 61-73.

Fisher, R. (2013). El diálogo creativo en el aula. Madrid: Ediciones Morata.

Freire, P., Flecha, R. y Aráujo A.M. (1997). A la sombra de este árbol. Barcelona: El Roure.

García, M. (2016). La fotografía como fuente histórica. Iber: Didáctica de las ciencias sociales, geografía e historia, 84, 47-52.

Gervereau, L. (2004). Voir, comprendre, analyser les images. París: La Découverte.

Girault, B. (2015). L'histoire, entre enseignement et recherche. Annales. Histoire, Sciences Sociales, 70(1), 141-149.

Gómez, C. J. y López, A. M. (2014). Las imágenes de los libros de texto y su función en la enseñanza de la Historia. Diseño de un instrumento de análisis. Enseñanza de las Ciencias Sociales, 13, 17-29.

Gómez, C. J. y Miralles, P. (2013). La enseñanza de la historia desde un enfoque social. Clío, History and History teaching, 39.

Gómez, C. J. y Miralles, P. (2015). ¿Pensar históricamente o memorizar el pasado? La evaluación de los contenidos históricos en la educación obligatoria en España. Revista de Estudios Sociales, 52, 52-68. DOI: 10.7440/res52.2015.04

Gómez, C. J., Miralles, P., López, R. y Prats, J. (2017). Las competencias históricas en el horizonte. Propuestas presentes y perspectivas de futuro. En R. López, P. Miralles y J. Prats (dirs.), Enseñanza de la historia y competencias educativas (pp. 215-234). Barcelona: Graó

Gómez, C. J., Ortuño, J. y Molina, S. (2014). Aprender a pensar históricamente. Retos para la historia en el siglo XXI. Revista Tempo e Argumento, 6(11), 5-27.

Habermas, J. (1987). Teoría de la acción comunicativa. Madrid: Taurus.

Haskell, F. (1994). La historia y sus imágenes: el arte y la interpretación del pasado. Madrid: Alianza.

Iglesias, M. (2009). Fotografías antiguas e historia local: una experiencia de investigación histórica con alumnado de secundaria. Iber: Didáctica de las ciencias sociales, geografía e historia, 60, 115-123.

Jaubert, A. (1986). Le Commissariat aux archives: Les photos qui falsifient l'histoire. París: Éditions Bernard Barrault.

Kitson, A., Steward, S. y Husbands, C. (2015). Didáctica de la Historia en secundaria obligatoria y bachillerato. Ediciones Morata, SL. 
Kuhn, D., Hemberger, L. y Khait, V. (2016). Dialogic argumentation as a bridge to argumentative thinking and writing/La argumentación dialógica como puente para el pensamiento y la escritura argumentativa. Infancia y Aprendizaje, 39(1), 25-48.

Lanzardo, L. (1991). Immagine del fascismo: fotografie, storia, memoria. Milano: Angeli.

Lara, E. y Emilio, L. (2005) La fotografía como documento histórico-artístico y etnográfico: una epistemología. Revista de antropología experimental, 5, 1-28.

Lee, P. y Shemilt, D. (2011). The Concept that Dares not Speak its Name: Should Empathy Come Out of the Closet? Teaching History, 143, 39-49.

Lee, P. y Ashby, R. (2000). Progression in historical understanding among students ages 7-14. En P. Stearns, P. Seixas y S. S. Wineburg (eds.), Knowing, teaching, and learning history: National and international perspectives (pp. 199-222). Nueva York: New York University Press.

Lee, P., Dickinson, A. y Ashby, R. (1998). Researching children's ideas about history. International review of history education, 2, 227-251.

Lipman, M. (1988). Investigación filosófica. Madrid: Ediciones de la Torre.

López, R, Miralles, P. y Prats, J. (dirs.) (2017). Enseñanza de la historia y competencias educativas. Barcelona: Graó

López, R. (2014). La LOMCE y la competencia histórica. Ayer: Revista de Historia Contemporánea, 94, 273-285.

Mattozzi, I. (2004). Enseñar a escribir sobre historia. Enseñanza de las ciencias sociales: revista de investigación, 3, 39-48.

Ministerio de Educación, Instituto de Evaluación (2010). Ciencias en PISA. Pruebas liberadas. Secretaría General Técnica.

Mora, G. y Ortiz R. (2013). La enseñanza del «tiempo histórico»: problemas y propuestas didácticas. História \& Ensino, 19(1), 7-25. DOI: 10.5433/2238-3018.2013v19n1p7

Pagès, J. (2006). La comparación en la enseñanza de la historia. Clio \& Asociados. La Historia enseñada, 9, 17-35.

Pagès, J. y Santisteban, A. (2010). La enseñanza y el aprendizaje del tiempo histórico en la educación primaria. Cad. Cedes, Campinas, 30(82), 281-309.

Pantoja, A. (2010). La fotografía como recurso para la didáctica de la Historia/The photography as a resource for teaching History. Tejuelo, 9(1), 179-194.

Prats, J. y Santacana, J. (2011). Enseñar a pensar históricamente: la clase como simulación de la investigación histórica. En J. Prats (coord.), Didáctica de la geografía y la historia (pp. 6787). Madrid: Ministerio de Educación Cultura y Deporte, Secretaría General Técnica.

Rodríguez de las Heras, A. (2009). Metodología para el análisis de la fotografía histórica. Espacio, tiempo y forma. Serie V, Historia contemporánea, 21, 19-35.

Rodríguez de las Heras, A. (2010). L'ús pedagògic de la fotografia histórica/Pedagogical use of historical photography. Educació i Història: Revista d'Història de l'Educació, 15, 41-54.

Sáiz, J. y Domínguez, J. (2017). Aprender sobre la historia: competencias metodológicas en educación secundaria. En R. López, P. Miralles y J. Prats (dirs.), Enseñanza de la historia y competencias educativas (pp. 23-48). Barcelona: Graó.

Sáiz, J. y López, R. (2015). Competencias y narrativas históricas: El pensamiento histórico de estudiantes y de futuros profesores. Revista de Estudios Sociales, 52, 87-101.

Sant, E., Pagès, J., Santisteban, A., González-Monfort, N. y Oller, M. (2014). Narrativas y discursos: ¿cómo podemos analizar la competencia narrativa del alumnado en el aprendizaje de la Historia? Clio \& asociados, 18, 166-182.

Searle, J. R. (1969). Speech acts: An essay in the philosophy of language (Vol. 626). Cambridge University Press.

Searle, J. R. (ed.) (1971). The philosophy of language (Vol. 39). Londres: Oxford University Press. 
Sega M.T. (1988), La storia scritta con la luce. La fotografia come fonte storica e La storia per immagini. L'uso della fotografia nella didattica della storia. I viaggi di Erodoto, 4, 58-71; 146-155.

Seixas, P. y Peck, C. (2004). Teaching historical thinking. En A. Sears e I. Wright (eds.), Challenges and Prospects for Canadian Social Studies (pp. 109-117). Vancouver: Pacific Educational Press

Seixas, P., Morton, T., Colyer, J. y Fornazzari, S. (2013). The big six: Historical thinking concepts. Toronto: Nelson Education.

Swartz, R., Costa, A., Beyer, B., Reagan, R. y Kallick, B. (2013). El aprendizaje basado en el pensamiento. Madrid: SM.

Velasco, J. A. y Alonso, L. (2008). Sobre la teoría de la educación dialógica. Educere, 12(42), 461470.

Voss, J. F. y Wiley, J. (2006). Expertise in History. En N.C.K.A. Ericsson, P. Feltovich y R.R. Hoffman (eds.), The Cambridge Handbook of Expertise and Expert Performance (pp. 17462424). Cambridge: Cambridge University Press.

Wells, G. (2001). Indagación dialógica: hacia una teoría y una práctica sociocultural de la educación. Barcelona: Paidós.

Wineburg, S. (2001). Historical thinking and other unnatural acts. Charting the future of teaching the past. Filadelfia: Temple University Press.

\section{CÓMO CITAR ESTE ARTÍ́CULO}

Gudín, E. y Chávarri, S. (2019). Fotografía en el aula para el desarrollo del pensamiento histórico. Didáctica de las ciencias experimentales y sociales, 37, 19-36. DOI: 10.7203/DCES.37.13316 